\title{
Pengaruh Proses Pembubutan Muka (Facing) pada Arah Forward dan Backward Terhadap Besarnya Defleksi yang Terjadi serta Daya Permesinan yang Dibutuhkan
}

\author{
Rusnaldy*, Mohammad Tauviqirrahman, Yudhi Prasetyo \\ Departemen Teknik Mesin, Fakultas Teknik, Universitas Diponegoro \\ Jl. Prof. Soedarto, SH, Kampus Undip Tembalang, Semarang \\ *E-mail: rusnaldy@undip.ac.id
}

\begin{abstract}
This paper presents an investigation of the effects of face turning process, i.e forward facing and backward facing, on machining deflection and machining power. The cutting insert used in this study was tungstein carbide having designation SDJCR 2020 K11Kyocera. The St 90 steel bar was used as workpiece in these experiments using lathe machine within the factors of spindle speed (500 rpm), feed rate $(0,4 \mathrm{~mm} / \mathrm{rev})$, depth of cut $(1 \mathrm{~mm})$, dry cutting and actual final cutting thickness of facing plane $(0,3 \mathrm{~mm})$ from initial thickness of $5 \mathrm{~mm}$. The results show that forward facing has smaller machining deflection than backward facing. Machining deflection increases with an decrease final cutting thickness of facing plane. Another results show that forward facing needed higher machining power compared to backward facing.
\end{abstract}

Keywords: face turning process, forward facing, backward facing, machining deflection, machining power

\begin{abstract}
Abstrak
Makalah ini membahas tentang pengaruh proses facing terhadap besarnya defleksi yang terjadi pada benda kerja terutama pada bagian facenya yang dikurangi ketebalannya dari $5 \mathrm{~mm}$ hingga $0,3 \mathrm{~mm}$. Proses facing yang digunakan disamping menggunakan pergerakan pahat pada arah forward juga digunakan pergerakan pahat pada arah backward. Disamping itu besarnya daya permesinan yang digunakan juga diukur untuk melihat tingkat keekonomisan proses facing pada arah forward dan backward. Parameter proses permesinan yang digunakan adalah putaran spindel sebesar $500 \mathrm{rpm}$, feeding sebesar $0,4 \mathrm{~mm} / \mathrm{rev}$, depth of cut sebesar $1 \mathrm{~mm}$ dan kondisi permesinan tanpa menggunakan cairan coolant. Dari hasil eksperimen diperoleh bahwa proses facing pada arah forward menghasilkan defleksi yang lebih rendah dibanding proses facing pada arah backward. Semakin tipis bagian face pada benda kerja yang dihasilkan semakin besar defleksi yang terjadi. Namun, facing pada arah forward ternyata membutuhkan daya permesinan yang lebih besar dibanding pada arah backward.
\end{abstract}

Kata kunci: Proses facing, arah forward, arah backward, defleksi, daya permesinan

\section{Pendahuluan}

Proses bubut muka (facing) adalah proses pergerakan pahat pada sisi sebelah kanan terhadap sumbu pusat benda kerja yang berputar. Proses facing juga dapat didefinisikan sebagai proses pemotongan ujung benda kerja untuk menghasilkan permukaan yang rata. Proses facing menggunakan arah pemakanan melintang dan biasanya merupakan proses awal dari pengerjaan benda kerja dengan menggunakan mesin bubut.

Penelitian prosesfacing secara eksperimental telah dilakukan oleh beberapa peneliti untuk menyelidiki kinerja proses pemesinan pada mesin bubut. Di mulai dari facing dengan material mild steel [1], kemudian berkembang pada proses pemesinan dengan material alloy steel [2], serta penggunaan material untuk komponen produksi seperti Matrix Composites [3]. Penelitian tentang facing juga dilakukan dengan menggunakan $\mathrm{SiCp} / \mathrm{Mg}$ metal matrix composites sebagai material percobaan [4].

Ada beberapa metode proses facing pada operasi mesin bubut. Penelitian proses facing dapat dilakukan dengan metode pemakanan searah dimana pahat potong bergerak dari permukaan keliling ke pusat benda kerja (arah forward) atau pemakanan berlawanan arah dimana pergerakan pahat dari pusat ke permukaan keliling benda kerja (mesin bubut) yang berputar searah jarum jam [5]. Metode ini dapat diterapkan juga untuk benda kerja dengan putaran berlawanan arah jarum jam di mana pahat bergerak dari permukaan keliling ke pusat benda kerja (arah backward).

Pada studi ini, proses facing coba dilakukan untuk mendapatkan benda kerja dengan face yang tipis (thin face). Proses pemotongannya menggunakan konsep yang sama dengan yang digunakan untuk menghasilkan thin wall, dimana thin wall merupakan perkembangan terkini dari proses permesinan untuk menghasilkan komponen dengan ketebalan yang setipis mungkin. Sebagai contoh atas apa yang telah dilakukan oleh Gerasimenko dkk. serta Fischer dan Eberhard. 
Gerasimenko, dkk. melakukan penelitian tentang turning thin walled pada tubular part untuk menyelidiki tentang tool displacement dan material removal, yang mempunyai potensi meningkatkan chatter yang berkorelasi dengan surface roughness yang dihasilkan serta potensi kerusakan pada tool [6].

Sementara itu Fischer dan Eberhard juga melakukan penelitian tentang proses pembubutan thin wall cylinder untuk menyelidiki adanya vibrasi beserta efeknya pada workpiece, tool dan machine [7]. Kedua penelitian diatas menggunakan proses cylindrical turning dalam proses pemotongannya.

Indikator keberhasilan dari proses facing dengan arah forward dan backward adalah dilihat dari besar kecilnya defleksi yang terjadi. Selain itu besarnya daya permesinan yang terjadi juga akan dijadikan sebagai indikator keberhasilan pada studi ini.

\section{Material dan metode penelitian}

\subsection{Benda Kerja}

Baja St. 90 yang termasuk jenis medium carbon steel dengan kandungan karbon $0.38-0.45 \%$ dan kekerasan 36 HRC digunakan dalam penelitian ini. Bentuk dan dimensi benda kerja dapat dilihat pada Gambar 1.

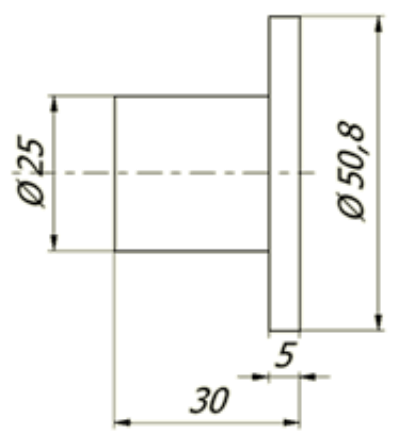

Gambar 1. Benda kerja

\subsection{Pahat}

Pada penelitian ini pahat Kyocera insert carbide (uncoating) dengan jenis SDJCR 2020 K11 dengan pemegang pahat (tool holder) Seco tool digunakan.

\subsection{Parameter Proses}

Empat parameter proses permesinan dibuat konstan, yaitu putaran spindel sebesar $500 \mathrm{rpm}$, feeding sebesar 0,4 $\mathrm{mm} / \mathrm{rev}$, depth of cut sebesar $1 \mathrm{~mm}$ dan tanpa menggunakan cairan pendingin (coolant). Proses facing, baik forward maupun backward, digunakan untuk menipiskan benda kerja bagian face benda kerja dari 5 mm hingga ketebalan face menjadi $4 ; 3 ; 2 ; 1,5 ; 1 ; 0,5 ; 0,3$ mm. Hasilnya kemudian diukur penyimpangan geometrinya pada arah radial (tegak lurus sumbu benda) hasil proses facing.

\subsection{Pengukuran Defleksi}

Defleksi diukur dengan cara mengukur penyimpangan geometri benda kerja sesudah proses facing, baik untuk arah forward maupun backward. Pengukuran defleksi menggunakan dial indicator dengan ketelitian $0.01 \mathrm{~mm}$. Pengukuran dilakukan secara langsung pada saat benda kerja masih terjepit pada chuck mesin bubut.

Dial indicator diletakkan pada eretan atas mesin bubut, dengan ujung sensor peraba menempel permukaan thin face benda kerja. Kemudian eretan digerakkan arah melintang sehingga ujung sensor peraba pada alat ukur mampu mendeteksi seberapa besar defleksi yang terjadi pada thin face.

\subsection{Pengukuran Daya Permesinan}

Daya permesinan selama proses facing ditentukan dengan cara mengukur kuat arus motor listrik pada saat pembebanan ketika proses facing berlangsung.Pengukuran kuat arus dilakukan pada kabel power yang menuju ke motor listrik. Pada panel listrik mesin terdapat tiga buah kabel power yang merupakan outputdari magnetic contactor. Kabel tersebut biasanya di beri simbol RST dengan warna merah, kuning, biru. Kemudian digital AC clampmeterdigunakan pada salah satu kabel tersebut untuk mendapatkan nilai arus listrik yang mengalir pada motor listrik. Pengukuran menggunakan Kyoritsu digital AC clamp meter. Data berupa arus listrik (ampere) nantinya akan diubah dalam bentuk daya pemesinan (watt).

\section{Hasil dan pembahasan}

\subsection{Besarnya Defleksi yang Terjadi}

Gambar 2 memperlihatkan benda kerja hasil proses facing pada arah forward dan backward dari ketebalan face 5 mm hingga 0,$5 ; 1 ; 1,5$ dan $2 \mathrm{~mm}$. Sementara itu pada gambar 3 dapat dilihat hasil pengukuran defleksi yang telah dilakukan. Pada gambar 3 terlihat bahwa semakin tipis material yang mengalami proses facing, semakin besar defleksi 
yang terjadi. Dari hasil yang diperoleh juga terlihat bahwa proses facingpada arah forward menghasilkan defleksi yang lebih kecil dibandingkan dengan facing yang menggunakan metode pemakanan backward. Defleksi terbesar terjadi pada proses facing dengan menggunakan metode pemakanan pada arah backward untuk tebal face 0,3 mm, yaitu sebesar $0,2 \mathrm{~mm}$.

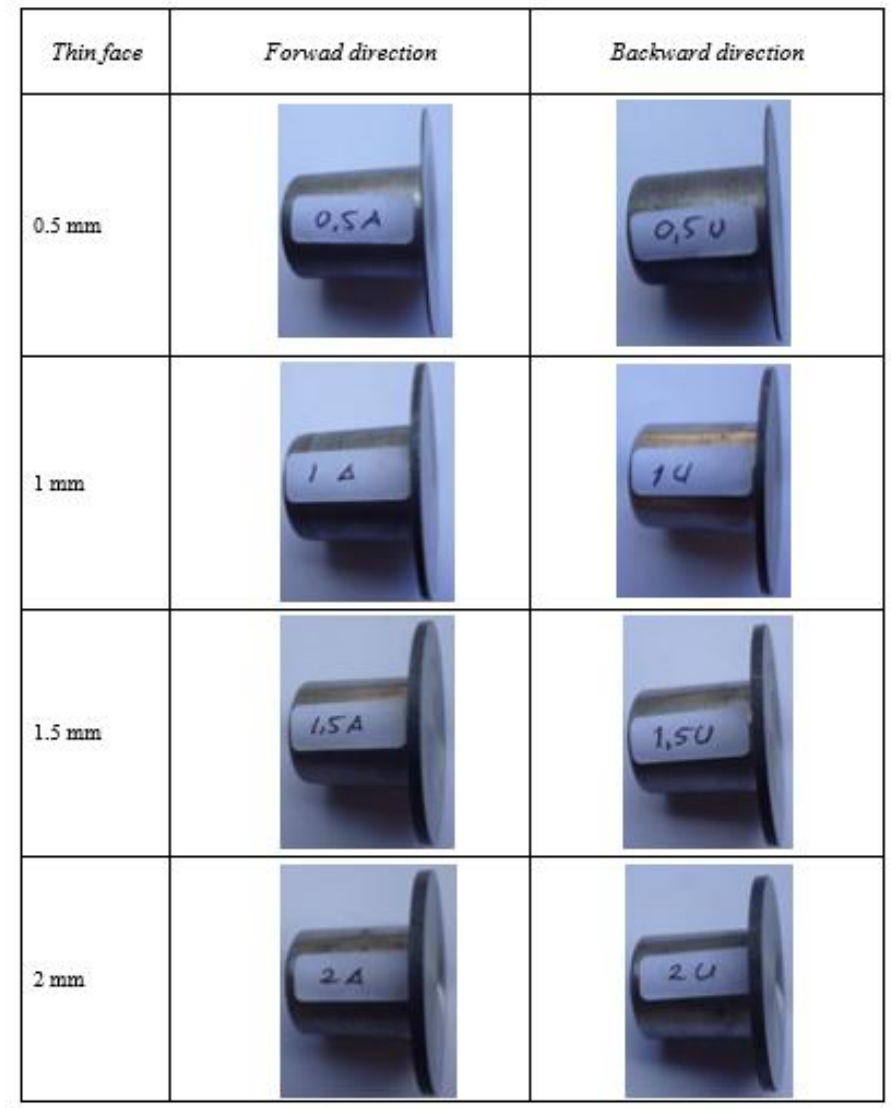

Gambar 2. Benda kerja setelah proses facing

Untuk proses facing dengan ketebalan benda kerja menjadi 2, 3, dan $4 \mathrm{~mm}$ terlihat bahwa defleksi antara proses facing arah forward dan backward relatif sama besarnya. Pada ketebalan-ketebalan ini nilai defleksi yang terjadi sekitar $0.01 \mathrm{~mm}$ yang merupakan nilai terkecil dari alat ukur yang dapat dicapai. Sehingga pada kondisi ini dapat dikatakan bahwa benda kerja masih cukup kakuuntuk menahan tekanan yang dapat mengakibatkan terjadinya defleksi. Semakin tipis geometri benda semakin besar defleksi yang dihasilkan, kondisi ini berkaitan dengan inersia penampang benda yang terkena gaya.

Dari hasil penelitian yang dilakukan oleh Huang, dkk menunjukkan bahwa proses permesinan pada thin wall biasanya memiliki sifat low rigidity pada saat proses proses permesinan berlangsung dan gaya potong serta suhu pemotongan juga dapat menyebabkan terjadinya defleksi $[8,9]$. Kondisi ini tentunya sangat merugikan karena dapat mengakibatkan permasalahan pada keakuratan dimensi dan surface integrity pada benda kerja yang dihasilkan. Selain itu adanya tegangan sisa yang terjadi setelah proses permesinan juga merupakan salah satu faktor terjadinya defleksi.

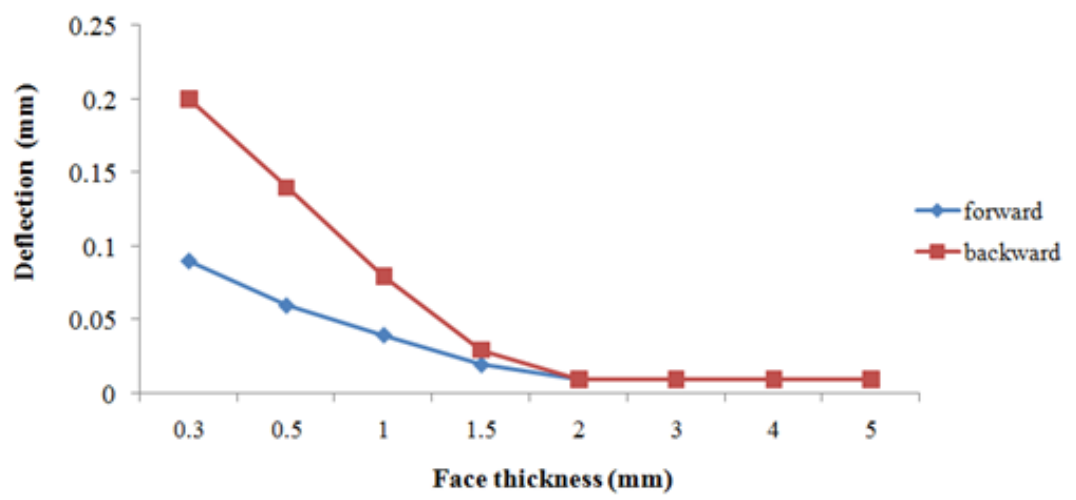

Gambar 3. Besarnya defleksi yang terjadi pada berbagai ketebalan face pada benda kerja 


\subsection{Besarnya Daya Permesinan}

Untuk mengetahui besarnya daya permesinan yang dibutuhkan pada proses facing dengan arah forward dan backward, parameter feeding yang digunakan divariasikan, yaitu sebesar 0,$1 ; 0,2 ; 0,3$ dan $0,4 \mathrm{~mm} / \mathrm{rev}$. Data pengukuran besarnya arus yang terjadi untuk setiap besarnya feeding pada arah forward dan backward dapat dilihat pada Tabel 1.

Tabel 1. Besarnya Arus Listrik yang Terjadi Saat Proses Facing Dilakukan

\begin{tabular}{cccc}
\hline \multirow{2}{*}{ Feeding $(\mathrm{mm} / \mathrm{rev})$} & \multicolumn{2}{c}{ Arus listrik (A) } \\
\cline { 2 - 4 } & Arah Forward & Arah Backward \\
\hline 0.1 & 4.5 & 4.4 \\
0.3 & 4.6 & 4.5 \\
0.4 & 4.7 & 4.6 \\
\hline
\end{tabular}

Daya pemesinan dapat dihitung dengan rumus : $P=V . I \sqrt{3} \cos \emptyset$

Dimana :

$\mathrm{P}=$ Daya pemesinan (Watt)

$V=$ Tegangan yang bekerja (Volt)

$I=$ Kuat arus (Ampere)

$\cos \emptyset=$ Power factor

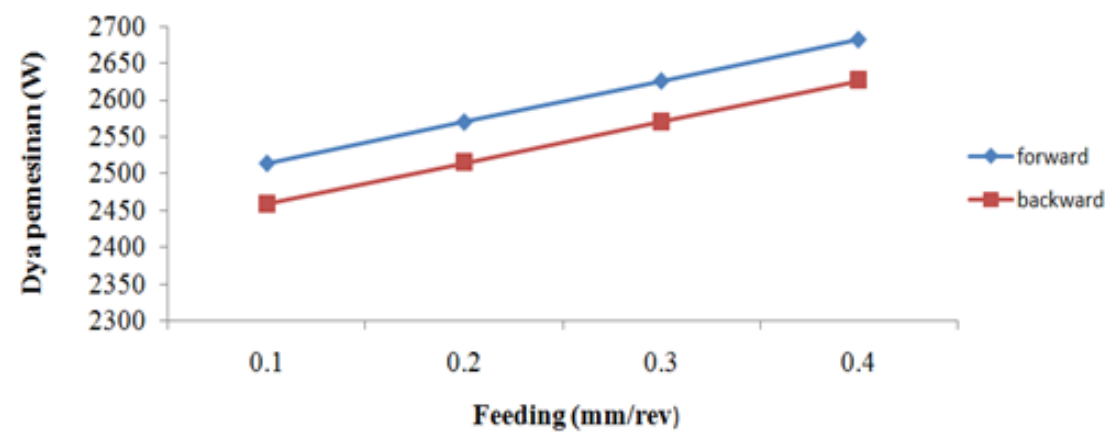

Gambar 4. Besarnya daya permesinan yang terjadi pada berbagai variasi feeding

Gambar 4 menunjukkan besarnya daya permesinan yang dibutuhkan pada proses facing arah forward dan backward pada berbagai variasi besarnya feeding. Untuk facing dengan arah forward dengan parameter feedingsebesar $0.1,0.2,0.3,0.4 \mathrm{~mm} /$ revmembutuhkan daya pemesinan sebesar 2514, 2570, 2626 dan 2682 watt. Sedangkan untuk facing dengan arah backward dengan parameter besar feeding yang sama membutuhkan daya pemesinan sebesar 2458, 2514, 2570 dan 2626 watt. Dari hasil terlihat pula bahwa proses facing pada arah forward membutuhkan daya permesinan yang lebih besar dibanding arah backward.

Penelitian yang dilakukan oleh Geo dan D'cotha menunjukkan bahwa daya pemesinan berkaitan erat dengan material removal rate (MRR) [10]. Dimana kenaikan MRR mengakibatkan kenaikan daya pemesinan, sehingga dapat disimpulkan bahwa daya pemesinan merupakan fungsi dari MRR. Sementara itu, besarnyaMRR tergantung pada besarnya feeding (f), cutting speed (V) dan depth of cut (a). Sehingga peningkatan daya pemesinan yang telah dilakukan merupakan implikasi kenaikan feeding.

\section{Kesimpulan}

Dari hasil yang diperoleh maka dapat ditarik kesimpulan bahwa proses facing dengan arah forward menghasilkan defleksi yang lebih kecil dibanding dengan defleksi yang terjadi pada arah backward. Makin tipis face pada benda kerja yang dihasilkan makin besar pula defleksi yang terjadi. Kemudian daya permesinan yang dibutuhkan untuk melakukan proses facing dengan arah forward lebih besar dibanding dengan arah backward. Makin besar feeding makin besar pula daya permesinan yang dibutuhkan.

\section{Daftar Pustaka}

[1] Šolaja, V. 1958. "Tool-life testing by facing in a lathe". Wear 1, no. $6: 512-514$.

[2] Dorlin, Théo, Fromentin, G and Costes, Jean-Philippe. 2015. "Analysis and Modelling of the Contact Radius Effect on the Cutting Forces in Cylindrical and Face Turning of Ti6Al4V Titanium Alloy." Procedia CIRP 31: 185-190.

[3] Rao, CR Prakash, M. S. Bhagyashekar, and Viswanath, Narendra. 2014. "Studies on Intermittent Facing of Metal Matrix Composites Using Cryogenic Treated Carbide Inserts." Procedia Engineering 97: 930-940. 
[4] Pedersen, W and Ramulu, M. 2006."Facing SiCp/Mg metal matrix composites with carbide tools." Journal of materials processing technology 172, no. 3: 417-423.

[5] Šalak, A. et al. 2006. "New short time face turning method for testing the machinability of PM steels."Journal of Materials Processing Technology 176, no. 1: 62-69.

[6] Gerasimenko, A, Guskov, M. \& Lorong, P. 2015. "Variable compliance-related aspects of chatter in turning thinwalled tubular parts". 31, pp.58-63.

[7] Fischer, A \& Eberhard, P, 2011. "Simulation-based stability analysis of a thin-walled cylinder during turning with improvements using an adaptronic turning chisel".

[8] Huang, Y, et al, 2012. "Finite Element Analysis of Machining Thin-Wall Parts": Error Prediction and Stability Analysis.

[9] ASM Metals Handbook Vol. 16 Machining Processes, ASM International, 1988

[10] Geo, R. \& D'cotha, J.S., 2014. “Effect of Turning Parameters on Power Consumption in EN 24 Alloy Steel using Different Cutting Tools". 2(6). 